only a few of them. In 2006 we counted 2,952 antelopes migrating east, of which $98.17 \%$ crossed by using the wildlife underpasses.

A highway built in the 1950s runs parallel to the railway, at about 500-1,500 metres away in our research area. (Outside our research area, the distance between road and railway ranges from 200 metres to 35 kilometres.)

The antelopes usually wait for a lull in the heavy flow of daytime traffic before hurrying across the road. Some animals even forage along the highway, seemingly ignoring the cars and trucks.

It seems, then, that the Tibetan antelopes have largely adapted to the presence of the Qinghai-Tibet railway. As the area develops further, care must be taken to ensure that these animals can continue their ancient pattern of migration.

Qisen Yang, Lin Xia

Institute of Zoology, Chinese Academy of

Sciences, Beijing 100101, China

\section{Vaccine trial provided valuable information}

SIR - Your Editorials 'Broken promises' and 'Mismanaged measures' (Nature 452, 503 and $504 ; 2008)$ seem to be contradictory. In the former, you excoriate the research community for running human efficacy trials for AIDS vaccines, whereas in the latter you complain about the use of surrogate end points.

You were right in the second Editorial. Without human efficacy trials on AIDS vaccines, we have had to rely on surrogate mainly preclinical - end points.

Until the Merck trial, we were searching in a wilderness of preclinical data. The Merck trial, although it unfortunately did not show efficacy, taught us more than all the surrogate experiments.

Without efficacy data in humans, particularly when we are dealing with a human viral disease that lacks a good animal model, we are always guessing. To have experimental correlates of human efficacy would be wonderful, but we are still a long way from that situation. Meanwhile, you should be supporting more human experimentation, not less.

\section{David Baltimore}

California Institute of Technology, 1200 East California Boulevard, Pasadena, California 91125, USA

\section{NIH funds support more than a researcher's own lab}

SIR - According to your News story ' 222 NIH grants: 22 researchers' (Nature 452, 258-259; 2008), I receive a large number of dollars from the US National Institutes of
Health (NIH) for 'cancer research'. As any knowledgeable reader will guess, more than $90 \%$ of that supports institutional activities, such as our Comprehensive Cancer Center at Memorial Sloan-Kettering, and not my own research laboratory. The story's bar chart may provide a source of (misleading) gossip, but it does not usefully serve readers looking for insight into the current crisis of funding at the NIH.

Harold Varmus

Memorial Sloan-Kettering Cancer Center 1275 York Avenue, New York 10021, USA

\section{NIH: grants revamp needs grounding in evidence}

SIR - Further to your News story 'Revamp for NIH grants' (Nature 451, 1035; 2008), the final draft of the US National Institutes of Health (NIH) 2007-08 peer-review selfstudy report tackles a critical set of issues for us grantees and reviewers. We all want an efficient and stable system; we all particularly care about junior investigators. But the solutions need to be grounded in evidence.

As you point out, a back-of-the-envelope calculation shows that eliminating more than two grants per investigator would allow a $5 \%$ increase in the number of grants. But is this better? Another casual calculation shows that requiring all grants to be shared by two investigators would more than double the number of grantees. So?

How do we know that eliminating amended applications will help? Amended applications are what keeps everyone honest. Without the back-and-forth of peer review, efforts by the NIH will degenerate into the dismal and ad hoc review process that characterizes many other agencies. And I would be reluctant to review the expanded load of always-new proposals.

Would a shorter application really enhance the quality of research or the efficiency of the review process? I don't want to spend extra time looking for lost key information. Is this a good idea? Why don't we study it?

Likewise, it is unclear whether using more than four reviewers would enhance the system or bring it to a screeching halt owing to the huge burden of review.

Also, what is the evidence that giving more R01 grants (individual grants that are the mainstay of extramural funding through the NIH) for early-career investigators will work in attracting the best and brightest to the life sciences and biomedical research? The issue is complex. I am not sure whether attaining that first R01 is the solution: it is the ability to stay there in a healthy and productive career.

Some suggestions are 'pilots', which should be applauded, but again there is little discussion of what is being measured and how.

It is high time for the NIH to conduct research on the review process itself. With hundreds of study sections meeting and thousands of applications reviewed every year, the material is there for retrospective analysis and for prospective studies that test specific hypotheses and interventions.

Perhaps the peer-review self-study should have submitted an R01 application on the proposed changes.

Yusuf A. Hannun

Department of Biochemistry and Molecular Biology, Medical University of South Carolina, Charleston, South Carolina 29425, USA

\section{NIH: researchers lose out to war, not to each other}

SIR - In your News story ' 222 NIH grants: 22 researchers' (Nature 452, 258-259; 2008), you contrast the concerns of junior investigators in the face of the flat budget of the US National Institutes of Health (NIH) with the comparative prosperity of a handful of their senior colleagues. Against this, I would argue that your review of grant numbers is flawed. It is absurd to consider supplements to parent grants, such as centresupport grants or training add-ons, as separate grants. Training grants should not be seen as counter to the self-interest of junior investigators. Also, you should have explained that junior investigators are supported by large centres or networks (in which hundreds of junior investigators may be engaged), although the NIH demands a single administrative leader - therefore a large grant is attributed to one person, often with many centres or supplements.

The end of the rise in funding for the NIH corresponded to the start of the war in Iraq, with its no-bid multibillion-dollar contracts and support of 150,000 Americans overseas. Half-a-trillion dollars (a very conservative estimate) has been spent there during the past five years, nearly four times the annual NIH budget in each of those years. The costs show no signs of abating - and all this in the context of tax cuts and economic recession.

So Nature should keep asking the tough questions about NIH funding decisions and effort-reporting policies. But please consider alternatives to your simplistic thesis.

Sten $\mathrm{H}$. Vermund

Institute for Global Health, Vanderbilt University School of Medicine, 319 Light Hall, 2215 Garland Avenue, Nashville, Tennessee 37323-0242, USA

Contributions to Correspondence may be submitted to correspondence@nature.com. Please see http://tinyurl.com/373jsv. 